\title{
Diversidade sexual e homofobia na escola: (des) conhecimento e vivências de docentes
}

\section{Resumo}

Elaine de Jesus Souza Universidade Federal do Rio Grande do Sul

Joilson Pereira da Silva

Claudiene Santos

Universidade Federal de Sergipe

A diversidade sexual que permeia a escola sofre inúmeros preconceitos e discriminações em decorrência da heteronormatividade. A carência de abordagem das temáticas sexualidade e gênero na formação docente dificulta a inclusão da diversidade sexual na escola e a desconstrução da homofobia. Essa pesquisa qualitativa objetivou analisar as concepções de educadores/as acerca da diversidade sexual e da homofobia na escola. Para tanto, empregou-se o método de análise de conteúdo categorial temática. Os resultados evidenciaram lacunas no conhecimento dos/as docentes acerca da diversidade sexual e das distintas faces da homofobia. Assim, salienta-se a imprescindibilidade de mudanças curriculares e ações pedagógicas que ampliem os conhecimentos dos/as educadores/as sobre essas temáticas.

Palavras-chave: Diversidade. Homofobia. Docentes.

\section{Sexual diversity and homophobia at school: (un)familiarity and experiences of teachers}

\begin{abstract}
The sexual diversity that permeates the school is submitted to numerous prejudices and discrimination due to heteronormativity. The lack of thematic approach to sexuality and gender in teacher's education hinders the inclusion of sexual diversity at school and the deconstruction of homophobia. This qualitative study aimed to analyze the conceptions of teachers about sexual diversity and homophobia at school. For this, we used the method of thematic categorical content. The results showed gaps in knowledge of teachers about sexual diversity and the different faces of homophobia. Thus, we highlights the need of curriculum changes and educational activities that expand the knowledge of educators on these issues.
\end{abstract}

Keywords: Diversity. Homophobia. Teachers. 


\section{Diversidad sexual y la homofobia en la escuela: (des) conocimientos y experiencias de maestros}

\section{Resumen}

La diversidad sexual que se respira en la escuela sufre numerosos prejuicios y discriminación como resultado de la heteronormatividad. La falta de enfoque temático de la sexualidad y el género en la formación del profesorado dificulta la inclusión de la diversidad sexual en la escuela y la deconstrucción de la homofobia. Este estudio cualitativo tuvo como objetivo analizar las concepciones de los profesores sobre la diversidad sexual y la homofobia en la escuela. Para ello, se utilizó el método de análisis de contenido temático. Los resultados mostraron lagunas en el conocimiento de los maestros sobre la diversidad sexual y las diferentes caras de la homofobia. Por lo tanto, pone de relieve el carácter indispensable de cambios en los programas educativos y actividades que amplían el conocimiento de los educadores sobre estos temas.

Palabras clave: Diversidad. Homofobia. Profesores.

\section{Introdução}

A evidente diversidade na sociedade contemporânea é instigante, visto que as diferenças socioculturais, econômicas, políticas, físicas ou sexuais podem contribuir de forma significativa com o aprendizado, partilhas e enriquecimento do ser humano. Uma das instituições em que torna-se bastante visível a diversidade é justamente a escola onde predomina a pluralidade de gêneros e identidades sexuais, em grande parte das vezes, cerceadas pelos muros e amarras, que tentam enquadrar todos/as num padrão social arbitrário que limita e oprime o direito de ser e expressar, de forma segura e democrática, as diferenças.

A pluralidade de indivíduos que a escola abriga abre um leque de possibilidades para o aprendizado, pois as experiências e vivências dos "outros" podem viabilizar o crescimento e o amadurecimento pessoal e intelectual dos/ as jovens e também do corpo docente e administrativo escolar. A diversidade sexual que permeia o ambiente escolar pode constituir-se em oportunidades dialógicas para destacar as múltiplas dimensões e vivências das sexualidades e dos gêneros, de modo inclusivo. 
Contudo, os/as educadores/as, muitas vezes, esbarram em dificuldades pessoais e, devido a lacunas em sua formação, apresentam dificuldades de lidar e incluir a diversidade sexual nesse ambiente de aprendizado, o que reitera um contexto de marginalização e exclusão. Tal segregação ocasiona graves consequências na vida de jovens que não se enquadram nas normas sexuais e de gênero, tais como abandono dos estudos, depressão e suicídio, em decorrência dos preconceitos e discriminações sofridos.

Assim, este trabalho teve como objetivo analisar as concepções de educadores/as acerca da diversidade sexual e da homofobia na escola. A pesquisa buscou responder às seguintes questões norteadoras: (a) Quais os conhecimentos de educadores/as concernentes à diversidade sexual e à homofobia? (b) Quais as vivências dos/as educadores/as sobre a diversidade sexual e a homofobia na escola?

\section{Diversidade sexual, homofobia e heteronormatividade: construção de preconceitos e discriminações}

É indubitável que, hoje, se vive em mundo social diverso, já que a vida se desenrola em meio a contextos sociais, povoados por pessoas com variados marcadores sociais, tais como: identidades étnica, sexuais e de gênero, formação cultural, situação econômica, filiação política e crença religiosa (LOURO, 1997). Destarte, os indivíduos estão perpetuamente embutidos na diferença social (BLAINE, 2007).

No mundo contemporâneo quando se trata da atração ou desejo afetivo-sexual, não existe uma única forma, mas múltiplas vivências e expressões de sexualidade. Desse modo, coexistem diversas orientações afetivo-sexuais ou diferentes rumos do desejo afetivo-sexual, entre elas, a heterossexualidade, a homossexualidade e a bissexualidade, que representam um dos aspectos da diversidade sexual (FIGUEIRÓ, 2007; KAMEL; PIMENTA, 2008).

Outro aspecto da diversidade sexual envolve a identidade sexual e a identidade de gênero. As identidades sexuais constituem as formas como os indivíduos vivenciam suas sexualidades com outros indivíduos, podendo ser heterossexuais, homossexuais, bissexuais, entre outras. E as identidades de gênero referem-se ao modo como os indivíduos constroem histórica e 
Diversidade sexual e homofobia na escola: (des)conhecimento e vivências de docentes

socialmente suas masculinidades e/ou feminilidades, incluindo os transgêneros - travestis e transexuais (LOURO, 1997).

As práticas pedagógicas e os estudos contemporâneos que permeiam a instituição escolar têm evidenciado que, em nossa sociedade, a lógica binária opera com base em uma identidade legitimada como a norma, leia-se masculina, branca, heterossexual, de classe média e cristã, logo os sujeitos que não se enquadram em tais marcadores identitários são invisibilizados e/ou discriminados. No entanto, o conceito de gênero pressupõe que a constituição como homens e mulheres consiste em um processo mutável e inacabado que ocorre por meio das mais variadas práticas sociais, assim não é linear e completo, pois envolve diversas (re)construções ao longo da vida. Ademais, tal conceito evidencia que as pessoas nascem e vivem em tempos, ambientes e circunstâncias peculiares; em consequência, coexistem distintos e conflitantes modos de definir e vivenciar as feminilidades e masculinidades imbricados em relações de poder desiguais (MEYER, 2013), que constituem a heteronormatividade.

Embora a diversidade sexual perpasse todas as esferas sociais, costuma ser constantemente marginalizada e/ou excluída do exercício pleno da 114 cidadania, sobretudo em decorrência da heteronormatividade, que envolve a aprovação suprema da heterossexualidade como norma ou padrão social, nessa lógica, considerada legítima em detrimento das outras vivências e expressões de diversidade sexual. Dessa forma, os indivíduos que não se enquadram, no modelo heteronormativo, sofrem, cotidianamente, preconceitos e discriminações (FIGUEIRÓ, 2007; LOURO, 1997).

$\bigcirc$ preconceito se refere a percepções mentais negativas acerca de sujeitos e grupos socialmente inferiorizados, aliado às representações sociais que envolvem concepções preestabelecidas e normativas. A discriminação diz respeito à materialização nas relações sociais, de atitudes arbitrárias relacionadas ao preconceito, produzindo violação de direitos dos indivíduos e grupos sociais inferiorizados (RIOS, 2009). Dessa maneira, a discriminação é uma tradução prática do preconceito, pois envolve a exteriorização e materialização dos estereótipos e das distintas formas de preconceitos (FLEURY; TORRES, 2010). 
Ademais, Chochík (2006) explica que não é possível estabelecer um conceito unitário de preconceito, visto que depende das representações atribuídas ao alvo (indivíduo ou grupo social desvalorizado).

Nesse sentido, distinguem-se duas formas de expressão do preconceito: o flagrante (manifesto) e o sutil. O preconceito manifesto é definido como forma mais direta e aberta de expressar atitudes negativas, que envolve elevada rejeição à intimidade e às emoções positivas acerca dos indivíduos ou grupos sociais. Já o preconceito sutil representa uma forma mais silenciada, velada ou disfarçada de expressar opiniões contrárias referentes aos sujeitos ou grupos. Assim, embora possam manter certo contato íntimo e tolerância, os relatos que dizem respeito ao preconceito sutil deixam latente que os sujeitos estão agindo de maneira incorreta e condenável no contexto social, pois não possuem os valores adequados, nem se enquadram nas normas sociais (LIMA; VALA, 2004).

Nessa direção, são criados protótipos ou generalizações normatizantes que englobam estereótipos, ou seja, um conjunto de atributos ou características preestabelecidas acerca dos membros de determinado grupo social. Tais generalizações acabam gerando diversos preconceitos contra indivíduos e grupos sociais e são usados para justificar a discriminação (NOGUEIRA; SAAVEDRA, 2007), sobretudo contra sujeitos que não se enquadram no modelo heteronormativo.

Herek (2000) adota o termo preconceito sexual para se referir a todas as atitudes negativas com base nas identidades sexuais (lésbicas, gays, bissexuais) e de gênero (travestis e transexuais) distintas da heteronormatividade. Tal preconceito atinge também sujeitos heterossexuais que são rotulados de homossexuais por adotarem comportamentos e/ou papéis divergentes do modelo heteronormativo. Como os outros tipos, o preconceito sexual consiste em uma atitude negativa (uma avaliação ou julgamento) dirigida a um grupo social e seus membros, envolvendo antipatia e hostilidade.

Por outro lado, muitos/as estudiosas/as adotam o conceito homofobia de forma abrangente, não mais centrado somente no indivíduo e na sua "reação anti-homossexual", visto que passa a envolver aspectos culturais, educacionais, políticos, institucionais, jurídicos, antropológicos que demandam a reflexão, crítica e denúncia acerca da imposição de normas sexuais e de gênero (JUNQUEIRA, 2009; RIOS, 2009). 
Diversidade sexual e homofobia na escola: (des)conhecimento e vivências de docentes

Compreender a homofobia como forma de preconceitos e/ou discriminações (e demais violências daí decorrentes) contra indivíduos ou grupos sociais, em função de suas identidades sexuais e/ou de gênero pressupostas, permite que, nesse conceito, estejam incluídos a lesbofobia, gayfobia, bifobia, transfobia, ou seja, a "LGBTfobia" em geral (BRASIL, 20 12). Contudo, os diversos grupos invisibilizados reivindicam nomenclatura própria para se referir às discriminações perpetradas contra Lésbicas, Gays, Bissexuais, transgêneros/ LGBT em decorrência de suas especificidades.

Em síntese, a homofobia pode ser definida como:

[...] uma manifestação perversa e arbitrária da opressão e discriminação de práticas sexuais não heterossexuais ou de expressões de gênero distintas dos padrões hegemônicos do masculino e do feminino. Há várias expressões sociais da homofobia, desde os atos violentos de agressão física e restrição de direitos sociais até a imposição da exclusão às pessoas cujas práticas sexuais não são heterossexuais. A heteronormatividade da organização social fundamenta-se em falsos pressupostos de naturalização das práticas heterossexuais e no caráter desviante de outras práticas. Ou seja, apesar de haver uma relação de proximidade entre o silêncio sobre a diversidade sexual, a heteronormatividade e a homofobia, esses são três fenômenos sociais diferentes (LIONÇO; DINIZ, 2009a p. 52)

Em consequência da relação entre a homofobia e a heteronormatividade, salienta-se que esta representa a "[...] postura de aprovação social que a sociedade tem diante da heterossexualidade, considerando o relacionamento heterossexual como a única forma aceitável e válida de relação afetivo-sexual entre duas pessoas" (FIGUEIRÓ, 2007, p. 37).

Acrescenta-se o termo "heterossexismo" que constitui o sistema a partir do qual determinada sociedade organiza um tratamento segregacionista devido à identidade sexual. $\bigcirc$ heterossexismo assim como a homofobia constituem as duas faces da mesma intolerância contra a diversidade sexual. Por conseguinte, ao invés de serem negados e silenciados, deveriam ser denunciados com o mesmo rigor que o racismo e o antissemitismo (BORRILO, 2009). heterossexismo, quando estabelecido, manifesta-se em instituições culturais e organizações burocráticas, tais como o sistema jurídico e a linguagem, ocasionando a ideia de superioridade e privilégios a todos os que se enquadram no 
padrão e, em contraponto, causa opressão e prejuízos aos sujeitos/grupos de lésbicas, gays, bissexuais, travestis e transexuais e, até mesmo, a heterossexuais que se afastem do modelo heteronormativo (RIOS, 2009).

A íntima relação entre a homofobia e as normas de gênero se traduz tanto em concepções, crenças, valores, expectativas, quanto em atitudes, construção de hierarquias opressivas e mecanismos reguladores discriminatórios bastante amplos. Isso evidencia que as práticas homofóbicas admitem drásticas consequências a qualquer indivíduo que ouse descumprir as normas socialmente impostas sobre as representações de masculinidade e feminilidade (UUNQUEIRA, 2009).

\section{Homofobia: múltiplas faces de um preconceito}

Para Borrilo (2009), a homofobia constitui um fenômeno complexo e variado. Dessa forma, sua gravidade não consiste somente nas práticas de violência física, mas, também nas manifestações da violência não física, presente nas ofensas, na linguagem cotidiana e nas representações caricaturais que apontam lésbicas, gays, bissexuais e transgêneros como criaturas grotescas e desprezíveis, desvelando assim, práticas prejudiciais e dolorosas. Tais manifestações denominadas de injúria representam a imposição da homofobia afetiva e cognitiva na medida em que as expressões pejorativas e agressões verbais, quando pronunciadas, causam consequências sociais e psicológicas, visto que marcam a consciência e a vida dos sujeitos ofendidos.

A injúria homofóbica provoca traumas que ficam gravados na memória e no corpo, visto que a vergonha, timidez, insegurança são atitudes corporais, resultantes da hostilidade do mundo exterior ou social. Logo, um dos efeitos da injúria é a reconstrução da personalidade, da subjetividade e do próprio ser, que depreende o remodelamento da relação com os outros e com o mundo. Nesse quadro, a violência em estado puro, representada como homofobia psicológica, não é nada mais que a internalização paradigmática de atitudes e comportamentos contra os/as homossexuais, bissexuais, transgêneros, intersexuais e outros sujeitos que possam ser identificados com esse grupo (BORRILO, 2009).

Além disso, Borrilo (2009, p. 20) acrescenta que: 
Diversidade sexual e homofobia na escola: (des)conhecimento e vivências de docentes

Outras manifestações menos grosseiras, mas não menos insidiosas, exercem suas violências cotidianamente. Essa outra face da homofobia, mais eufemística e de caráter social, tem suas raízes na atitude de desprezo constitutiva da forma ordinária de temer e categorizar o outro. Se a homofobia afetiva (psicológica) se caracteriza pela condenação da homossexualidade, a homofobia cognitiva (social) pretende simplesmente perpetuar a diferença homo/hetero, pregando a tolerância, uma clemência policiada dos ortodoxos para com os hereges. Nesse caso, não há rejeição aos homossexuais; no entanto, não choca ninguém o fato de eles não gozarem dos mesmos direitos que os heterossexuais (BORRILO, 2009, p. 20).

A homofobia cognitiva funda um saber acerca da diversidade sexual baseado em preconceitos que a reduzem a estereótipos, ou seja, engloba não somente preconceitos e discriminações contra as identidades sexuais, mas também contra qualquer manifestação de afeto entre indivíduos do mesmo sexo ou identidades de gênero que diferem dos padrões sociais. Além disso, devido à complexidade desse fenômeno, adverte-se que essa primeira distinção entre homofobia psicológica (individual) e homofobia cognitiva (social) 118 apesar de ser necessária, não é suficiente, visto que essa temática demanda outras classificações que permitem delimitar uma série de situações que, sob o mesmo termo, agrupam variadas formas de antipatia por todos os sujeitos que destoam das normas sexuais e de gênero. Em consequência da extensão desse termo, é estabelecida uma segunda distinção entre homofobia geral e homofobia específica (BORRILO, 2009).

Desse modo, a homofobia geral é caracterizada por uma manifestação de sexismo, ou seja, a discriminação de indivíduos em razão de seu sexo biológico e, sobretudo, devido às identidades de gênero. Assim, essa forma de homofobia encobre as fronteiras do gênero e pode ser definida como a discriminação contra pessoas que demonstram, ou a quem são atribuídas, certas características (qualidades, defeitos, comportamentos) consideradas do outro gênero, sendo relacionada aos estereótipos de gênero (BORRILO, 2009; WELZER-LANG, 20011. Já a homofobia específica representa uma forma de intolerância relativa, principalmente, a gays e lésbicas. Por isso, alguns/as autores/as propuseram utilizar os termos "gayfobia" e "lesbofobia" para diferenciar as principais declinações da homofobia específica (BORRILO, 2009, p. 23). Evidencia-se que "[...] a lésbica sofre uma violência particular advinda 
de um duplo menosprezo, pelo fato de ser mulher e pelo de ser homossexual. Diferentemente do gay, ela acumula discriminações contra o sexo e contra a sexualidade".

A homofobia engloba práticas discriminatórias intensas e cotidianas expressas, em diversos âmbitos sociais, por meio de distinções, exclusões, restrições e/ou preferências que anulam ou prejudicam o reconhecimento e o exercício igualitário de direitos humanos e liberdades fundamentais nos campos sociocultural, econômico ou em qualquer esfera da vida pública. Compreender a homofobia, nessa perspectiva ampla, permite elucidar que a qualificação de um ato como homofóbico não depende da intencionalidade ou da situação que ocasiona a lesão aos direitos humanos e liberdades fundamentais afetadas. Assim, a existência da discriminação homofóbica, proposital ou não, ocorre sempre que houver alguma espécie de lesão de direitos, decorrente da manifestação de preconceitos diante dos modos de ser e viver destoantes da heteronormatividade. Por isso, torna-se relevante analisar e se atentar para as formas intencionais (discriminação direta) e não intencionais (discriminação indireta) das práticas homofóbicas, uma vez que ambas lesionam direitos de forma grave e disseminada (RIOS, 2009).

Vale destacar que a forma intencional da homofobia está fundamentada na norma e, portanto, demonstra, explicitamente, a aversão e/ou desprezo aos grupos de lésbicas, gays, bissexuais e transgêneros por meio de condutas preconceituosas, bem como ocasiona diferenciações e injustiças contra tais grupos em diversas instâncias sociais. Em face dessa realidade, é importante levar em consideração o conceito da homofobia não intencional (discriminação indireta) e buscar problematizar, visando desconstruir essa forma de discriminação que "[...] é fruto de medidas, decisões e práticas aparentemente neutras, desprovidas de justificação e de vontade de discriminar, cujos resultados, no entanto, têm impacto diferenciado perante diversos indivíduos e grupos, gerando e fomentando preconceitos e estereótipos inadmissíveis" (RIOS, 2009, p. 76).

A homofobia, ao violar de forma intensa e permanente uma série de direitos humanos básicos, manifesta-se por meio de duas formas de violência: física e não física. A violência física atinge diretamente a integridade corporal, podendo até levar ao homicídio; por isso, é mais visível e considerada mais brutal. Já a violência não física, que também é grave e danosa, consiste, sobretudo, no não reconhecimento da diversidade sexual e na injúria homofóbica. 
O não reconhecimento configura um tipo de ostracismo social, pois nega valor às identidades sexuais e de gênero não hegemônicas, ocasionando condições para formas de tratamento degradantes e insultuosas aos grupos de lésbicas, gays, bissexuais e transgêneros (RIOS, 2009).

Para Louro (2009), a manutenção das diferentes formas de homofobia está relacionada ao não reconhecimento das múltiplas sexualidades e aos estereótipos de gênero. Então, a violência homofóbica é fortalecida através do investimento continuado e repetido em estratégias e táticas aparentes ou sutis, empregadas para reafirmar o equivocado princípio que defende que, como os seres humanos nascem biologicamente machos e/ou fêmeas, seu sexo biológico determinaria um de dois gêneros possíveis, masculino ou feminino. Aliada ao determinismo sexual, é justificada a ideia arbitrária de que existe uma única forma de desejo afetivo-sexual que, nessa lógica binária, deveria ser entre pessoas do sexo oposto.

Nota-se que as violências homofóbicas não possuem somente uma causa, pois são ocasionadas, reforçadas e mantidas por diversos fatores socioculturais e históricos fundamentados, sobretudo, em representações normativas e preconceitos em torno de sexualidade e de gênero que insistem em manter o 120 modelo heterossexual como hegemônico e marginalizar a diversidade sexual.

\section{Metodologia}

Essa pesquisa qualitativa foi realizada em uma escola pública do município sergipano Simão Dias. A escolha desse lócus deve-se à escassez de estudos referente a essa temática no interior de Sergipe. Houve a participação de dez professores/as do ensino médio, das disciplinas de Português, Matemática, Biologia, Geografia, História, Inglês, Educação Física, Química, Física e Sociologia. Essa escolha justifica-se por corresponderem às disciplinas obrigatórias, que deveriam abordar os temas transversais de modo interdisciplinar, como sexualidade e diversidade sexual. Todos os nomes dos/as docentes são fictícios.

Neste trabalho, foi utilizada a entrevista semiestruturada para coleta das informações, norteada por um questionário com perguntas abertas e fechadas, elaboradas com base na bibliografia estudada (DINIS, 2012 ; MADUREIRA, 2007; SILVAJÚNIOR, 2010; TOSSO, 20121. 
projeto foi aprovado pelo Comitê de Ética, tendo sido solicitada a autorização das escolas para os/as educadores/as participarem da pesquisa e, para a realização das entrevistas, os/as participantes assinaram termos de consentimentos livres e esclarecidos.

Para analisar as informações da pesquisa, adotou-se a análise de conteúdo categorial temática, que consiste em desmembrar o texto em unidades de sentido, ou seja, são determinadas as principais opiniões, crenças e concepções encontradas nas respostas das questões abertas da entrevista; posteriormente, essas unidades foram agrupadas em categorias de análise (BARDIN, 2011 ).

\section{Resultados e discussão}

Os resultados obtidos foram agrupados em duas categorias: "Diversidade sexual e Homofobia: o (des)conhecimento de educadores/as", que engloba as principais concepções dos docentes sobre esses temas, possibilitando compreender quais os conhecimentos foram adquiridos durante sua formação inicial e/ou continuada, e "Vivências de docentes acerca da diversidade sexual e da homofobia na escola", que inclui as principais experiências, atitudes e situações, vivenciadas pelos/as educadores/as em sala de aula.

\section{Diversidade sexual e homofobia: o (des)conhecimento de educadores/as}

Quando questionou-se aos/as docentes sobre o que entendiam por diversidade sexual, foram obtidas respostas convergentes, de modo geral, demonstrando lacunas no conhecimento concernente ao tema, sobretudo porque algumas representações estão pautada na ideia de "escolha ou opção". Isso pode ser notado nos seguintes relatos:

Opções sexuais variadas (PROF. ${ }^{a}$ VANUZA, 2013).

A pluralidade de opções sexuais que o indivíduo pode exercer (PROF. RAUL, 2013).

Grupos, ambientes onde existem homens e mulheres com distintas opções sexuais (PROF. RAFAEL, 2013). 
De modo semelhante, nas falas abaixo, embora não seja citada a ideia equivocada de "opção sexual", percebe-se uma representação da diversidade sexual ligada às identidades sexuais e de gênero e como algo que foge aos padrões de relacionamentos afetivo-sexuais, ou seja, que não se enquadram no modelo heteronormativo:

Diversos gêneros sociais (PROF. AFONSO, 2013).

Amplitude de relacionamento entre os grupos de categoria de identificação sexual (PROF. DIEGO, 2013).

É aquele que foge o relacionamento entre um homem e uma mulher (PROF. ${ }^{a}$ ARIELLA, 2013).

Em contrapartida, alguns/mas docentes revelaram que compreendem de modo mais coerente, demonstrando até algum conhecimento sobre o termo diversidade sexual.

A compreensão uma multiplicidade de entendimentos e/ou orientações sexuais (PROF. AMANDA, 2013).

São as variantes da sexualidade humana (PROF. aúllA, 2013).

É o nome dado às diferentes expressões da sexualidade. (PROF. DENIS, 2013).

Diz respeito às várias formas de orientação sexual (PROF. ELIAS, 2013).

As diversas falas apontam para um princípio de (re)conhecimento da diversidade sexual, embora permeado por ideias veiculadas pelo senso comum e por visões essencialistas. Para que os/as docentes consigam compreender a diversidade sexual além das leis naturais ou essencialistas, não como uma escolha ou opção, mas como uma construção social que envolve múltiplos fatores, é fundamental que conheçam sua amplitude e complexidade. A diversidade sexual inclui as diferentes práticas, vivências e expressões de sexualidade e de gênero, construídas no decorrer da vida humana a partir de aspectos históricos e socioculturais, e não por simples escolha, influência ou determinismos biológicos (LOURO, 1997, 2000; FIGUEIRÓ, 2007; KAMEL; PIMENTA, 2008; DINIS, 2008; JUNQUEIRA, 2009a). Assim, faz-se necessário que esse debate seja inserido na formação docente em todos os níveis. 
Quando foi perguntado aos/as docentes o que entendiam por homofobia, em sua maioria, as concepções apresentadas revelaram uma visão reducionista sobre esse tema, como se a homofobia incluísse somente a aversão, medo ou preconceito contra os homossexuais. Isso pode ser explicado pelo entendimento literal do termo e pela carência de conhecimentos acerca desses temas durante a graduação.

Preconceito contra os homossexuais, crime (PROF. ${ }^{a}$ VANUZA, 20131.

Sentimento forte da homossexualidade (PROF. JÚLIA, 2013).

Agressão física ou verbal a uma pessoa que fez a opção sexual por outra do mesmo sexo (PROF. RAUL, 2013).

Reação violenta ou não aos relacionamentos homossexuais (PROF. AFONSO, 20131.

Sentimentos e ou atitudes de aversão aos homossexuais (PROF. DIEGO, 2013).

É o medo do igual - aversão (PROF.a ARIELLA, 2013).

Medo ou receio de se conviver com homossexuais (PROF. DENIS, 20131.

Medo ou preconceito a homossexuais (PROF. ELIAS, 2013).

Intolerância e repugnação a pessoas do mesmo sexo no contato afetivo (PROF. RAFAEL, 2013).

A construção de um conceito de ser baseada na heteronormatividade, que não compreende outras como possíveis (PROF. ${ }^{a}$ AMANDA, 20131.

Embora a visão reducionista seja predominante, percebe-se uma aproximação do conceito de homofobia como aversão, temor, preconceito, violência e crime; isso, possivelmente, em decorrência de casos veiculados na mídia. Somente uma educadora demonstrou uma concepção mais ampla da homofobia, visto que destacou a questão de construção fundamentada no modelo heteronormativo, o que, de fato, é umas das principais características das práticas homofóbicas.

É necessário enfatizar que, embora o conceito de homofobia tenha sido empregado, inicialmente, para se referir a um conjunto de emoções negativas (aversão, desprezo, ódio ou medo) em relação à homossexualidade, 
essa noção foi alargada para englobar as múltiplas faces da violência homofóbica. Historicamente, entendê-lo daquela forma limitada, implicaria pensar o seu enfrentamento somente a partir de medidas direcionadas a minimizar os efeitos de sentimentos e atitudes de "indivíduos" ou "grupos homofóbicos", preterindo as instituições que nada teriam a ver com isso.

Contudo, a homofobia deveria ser representada como fenômeno psicológico e social que está ancorada nas complexas relações estabelecidas entre uma estrutura psíquica e uma organização social normativa que considera a heterossexualidade como ideal no âmbito afetivo-sexual. Outras manifestações menos grosseiras, mas insidiosas exercem suas violências cotidianamente, visto que essa outra face da homofobia mais eufemística e de cunho social ancora-se na atitude de desdém constitutiva de uma forma habitual de aprender e de categorizar o outro (BORRILO, 2009; 2010; JUNQUEIRA, 2009a), ou seja, uma forma normatizante de representar as diferenças, no caso, a diversidade sexual.

Quando se indagou aos/as professores/as sobre o que seria a homossexualidade (feminina ou masculina), ainda que as respostas tenham sido confusas, a maioria assinalou (no questionário) a alternativa "opção sexual", ou 124 seja, acreditam que o indivíduo escolhe o direcionamento do desejo afetivo-sexual. Entretanto, nas justificativas também são percebidas dúvidas, sobretudo na relação entre "escolher", "nascer assim" ou "ser influenciado pelo meio", bem como alguns/mas docentes assinalaram que a homossexualidade, além de "opção", também é uma "orientação sexual", o que denota desconhecimento sobre o sentido e a diferença entre esses termos. A saber:

Opção sexual. Todos são livres para optar, escolher sua opção (PROF. AFONSO, 2013).

Opção sexual. Acredito que a pessoa não nasce homossexual. É uma escolha (PROF. DENIS, 2013).

Opção sexual. Porque o indivíduo tem o direito de escolher sua sexualidade quando entra na puberdade, ou mesmo antes (PROF. RAUL, 2013).

Orientação sexual e Opção Sexual. Penso que quando não nasce com a pessoa, há uma opção, uma orientação (PROF. ELIAS, 2013). 
Elaine de Jesus Souza | Joilson Pereira da Silva | Claudiene Santos

Orientação sexual, Opção sexual e Outros. Sabemos que o meio pode influenciar o indivíduo, mas existem fatores genéticos que influenciam na escolha (PROF. RAFAEL, 2013).

Orientação sexual e Opção sexual. Entendo que as subjetividades são múltiplas, e por isso são possíveis as duas respostas (PROF. AMANDA, 20131.

Outros. Acredito que deve ter um pouco de genética e talvez algo relacionado à criação (PROF. ${ }^{a}$ VANUZA, 2013).

Em detrimento de representações normativas, os/as docentes precisariam buscar conhecimentos (numa formação continuada, por exemplo) para compreender que o termo "opção sexual" deveria ser substituído por orientação afetivo-sexual (que engloba a identidade sexual), pois o desejo afetivo-sexual não é uma opção consciente, mas uma questão complexa, perpassada pelas constituições subjetivas de cada um/a, a partir de suas vivências sociais. As identidades sexuais e de gênero resultam de um processo profundo que envolve diversos fatores sociais, culturais, emocionais, entre outros. Portanto, a homossexualidade e toda a diversidade sexual precisam ser compreendidas como algo que o indivíduo constrói no decorrer de suas vivências, por meio de um processo multifatorial e não determinado por escolhas ou influências de outros sujeitos (CAVALEIRO, 2009; FIGUEIRÓ, 2007; FURLANI, 2009; HENRIQUES, BRANDT, JUNQUEIRA, 2007; LOURO, 1997).

Em contraponto, duas educadoras demonstraram uma representação mais ampla, assinalando que a homossexualidade é uma "orientação sexual", desvelando a dimensão sociocultural, contudo no relato de uma das docentes, a dimensão biológica foi apontada. No relato de um educador, foi ressaltada a questão multifatorial, o que é condizente com a noção de construção envolvendo vários fatores.

Orientação sexual. Algo de mistério. E um tanto de cultura, outro de biológico (PROF. JúlLIA, 2013).

Orientação sexual. Acredito que sua sexualidade seja despertada durante o processo de relacionamento com você mesmo e com o outro, mas não de forma influenciável (PROF.a ARIELLA, 2013).

Outros (Não sei). Creio que é multifatorial, mas casos específicos podem ser avaliados de melhor maneira. Ainda não compreendo 
e creio que não compreenderei esse aspecto comportamental humano, pois é de difícil estudo (PROF. DIEGO, 2013).

conceito de orientação sexual refere-se às distintas formas de atração física e emocional que estão na base da discussão das vivências da homossexualidade e de outras identidades sexuais e de gênero (DINIS; ASINELLI-LUZ, 2007; FIGUEIRÓ, 2007; FLEURY; TORRES, 2010). Costa (1994) acrescenta ao termo orientação a palavra 'afetivo', para evidenciar que esse relacionamento não é somente de ordem sexual, mas também inclui o afeto e o amor, já que nem sempre afeto e sexo estão vinculados. Desse modo, o termo orientação afetivo-sexual é definido como a sensação interna de que um indivíduo possui a capacidade de se relacionar amorosa e/ou sexualmente com alguém, constituindo parte da identidade sexual, algo que pertence ao mundo interno ou psicológico do sujeito.

\section{Vivências de docentes acerca da diversidade sexual e da homofobia na escola}

Essa categoria destaca as vivências docentes em face da diversidade sexual no âmbito escolar, ainda que, na maioria dos casos, haja invisibilização e negação dos indivíduos com identidades sexuais e de gênero dissidentes da norma hegemônica, o que, entre outros motivos, acaba gerando as práticas homofóbicas contra tais sujeitos. A diversidade sexual e a homofobia, no contexto escolar, trazem inúmeros desafios para todos os membros dessa instituição, sobretudo, para os/as educadores/as que, apesar da carência de conhecimentos concernente às temáticas sexualidade, gênero e diversidade sexual, buscam promover a desconstrução da homofobia e a inclusão da diversidade.

Apesar do conhecimento parcial, seis educadores/as afirmaram que se sentem preparados/as para trabalhar e/ou conviver com alunos/as e colegas que possuem diferentes identidades sexuais e de gênero, sobretudo porque aprenderam a respeitar as diferenças. Logo, ficou evidenciado, nas falas de muitos docentes, que, mesmo não concordando com as identidades sexuais e de gênero não heterossexuais, acreditam que o respeito é a base para a convivência social. Todavia, é necessário enfatizar que a questão não envolve somente o respeito, mas, sobretudo o reconhecimento e a equidade. 
Elaine de Jesus Souza | Joilson Pereira da Silva | Claudiene Santos 달

Sim. Pois, o respeito pela diversidade deve prevalecer no convívio entre pessoas (PROF. RAUL, 2013 ).

Sim. Pois, já trabalho e não tenho problema algum. $\bigcirc$ importante e sempre o respeito (PROF. ${ }^{a}$ VANUZA, 2013).

Sim. Pois, costumo encarar e aceitar as coisas/situações, com naturalidade (PROF. ELIAS, 2013).

Sim. Porque fui educada desde muito cedo para respeitar as diferenças e estudei [...] (PROF. JúllA, 2013).

Sim. Porque acima de tudo precisamos respeitá-los enquanto pessoa humana e os trato sem diferenciação nenhuma. Mas temos as nossas fragilidades para algumas situações desse gênero em sala de aula (PROF.a ARIELLA, 2013).

Eu me sinto preparado devido à minha formação como homem que tenho bons valores e não discrimino as diferenças dos meus alunos e colegas. Acredito que o nosso trabalho ganharia mais qualidade com a quebra desse 'tabu' (conversar sobre o assunto) (PROF. RAFAEL, 2013).

As falas apontam para a necessidade de quebra de tabus, ao falar sobre o tema, o reconhecimento das dificuldades e a necessidade de formação, ainda que afirmem respeitar as diferenças. Ao compreender que os/as docentes possuem diversas concepções preestabelecidas, uma reeducação sexual poderia contribuir para a formação do/a educador/a. Cada indivíduo carrega os tabus, preconceitos e mitos que permeiam a sociedade de modo geral, sendo necessário refletir e problematizar as representações normativas, os preconceitos e as atitudes discriminatórias acerca da diversidade sexual. Para tanto, uma formação docente (inicial e continuada) seria fundamental para repensar a si mesmo e a educação sexual (FIGUEIRÓ; KAWATA; NAKAYA, 2010). Embora já existam cursos de graduação que tratem dos temas sexualidade e gênero, frequentemente tais disciplinas são optativas. Na Universidade Federal de Sergipe, a disciplina Corpo, Gênero e Sexualidade é ofertada na matriz curricular obrigatória da licenciatura em Biologia, desde 2014.

Para que os/as educadores/as consigam ir além do respeito e possam (re)conhecer a diversidade sexual na escola, torna-se necessário superar a carência na formação docente e buscar conhecimentos, por meio de uma formação continuada, cursos, eventos, entre outros, possibilitando aprendizados constantes e, assim, uma significativa reeducação sexual (FIGUEIRÓ; KAWATA; 
NAKAYA, 2010; PEREIRA, 2010) que seja capaz de promover a desconstrução de preconceitos em torno das múltiplas sexualidades.

No entanto, os/as demais docentes participantes afirmaram que não se sentem preparados/s para lidar e conviver com a diversidade sexual na escola, enfatizando, como principal motivo, a carência na formação docente com relação a essa temática. Cabe atentar também que o desconhecimento acerca desses temas constitui um dos principais fatores que impedem o reconhecimento da diversidade sexual e a promoção de ações pedagógicas para combater a homofobia na escola. A saber:

Sim. Para ter relações interpessoais harmoniosas, mas não para lidar com casos de homossexualismo [sic], em relação à orientação ou casos de agressões (PROF. AFONSO, 2013).

Nunca estamos formados ou preparados para a sala de aula. Sempre é possivel que ela tire o nosso chão (PROF. ${ }^{a}$ AMANDA, 2013).

Não. Pois, não há qualificação sobre esse tema de maneira satisfatória (PROF. DIEGO, 2013).

Não. Formação acadêmica deficiente (PROF. DENIS, 2013).

Em decorrência da carência na formação inicial e continuada aliada a outros fatores, muitos/as docentes sentem dificuldade em compreender e lidar com a diversidade sexual na escola. Assim, ao invés de acolher os/as alunos/as que não se enquadram na heteronormatividade e discutir questões relativas a essa temática, acaba-se por ignorá-los/as, como se o silenciamento os/as fizesse deixar de existir. Desse modo, o ocultamento e/ou negação dos indivíduos com diferentes identidades sexuais e de gênero representa uma forma que a escola encontra para preservar o padrão heteronormativo, evitando que os/as alunos/as enquadrados/as na "norma" possam transgredi-la ao adquirir conhecimentos acerca da diversidade sexual (LOURO, 1997).

Assim, essa invisibilização da diversidade sexual é recorrente nas escolas e nos instrumentos pedagógicos, em consonância subestimam-se os efeitos danosos (tanto físicos quanto psicológicos) que os preconceitos homofóbicos causam às crianças e jovens, em processo de desenvolvimento, mas, mesmo assim, são julgadas e discriminadas através da manutenção dos estereótipos de gênero (LOURO, 1997; LIONÇO; DINIZ, 2009). 
Sobre as principais práticas de violência (psicológica e/ ou física) contra estudantes não heterossexuais ou com identidades de gênero distintas do padrão heteronormativo, presenciadas pelos/as docentes no ambiente escolar, foram citadas (por todos/as os/as participantes): piadinhas e apelidos pejorativos, bem como foram destacadas (por sete professores/as): a incidência de insultos e zombarias; humilhações e exclusões, além disso, dois docentes enfatizaram a ocorrência de agressões físicas na escola aliada a outras práticas homofóbicas indiretas:

Piadinhas e apelidos pejorativos. Algumas diferenças na escola não têm sido toleradas principalmente por alunos no ensino fundamental. Por vezes, ouço piadinhas e apelidos para alunos que não cumprem o padrão heterossexual (PROF.' AMANDA, 2013).

Piadinhas e apelidos pejorativos. Outros: imitam o modo de falar e de caminhar (PROF. RAUL, 2013).

Agressões físicas; Insultos e zombarias; Humilhações; Exclusões; Piadinhas e apelidos pejorativos (PROF. DIEGO, 2013).

Além das práticas homofóbicas citadas, alguns/mas docentes relataram outras situações de preconceitos e discriminações, manifestadas na escola, cotidianamente, contra jovens que fogem às normas sexuais e de gênero. Entretanto, alguns/mas educadores/as chegam a expor que não sabem como agir diante dessas situações ou que "quando as percebem" costumam trabalhar ou dialogar sobre isso. No entanto, as ações pontuais, envolvendo demanda, evidenciam uma insuficiência no preparo, decorrente, sobretudo, da carência na formação docente, para combater ou, ao menos, reduzir a homofobia que permeia a escola e assombra a vida de diversos estudantes. Em suas falas:

De piadinhas já. Assim de apelidinhos, sabe? Ô fulano! Aí na hora você tem que ser o educador. E fazer respeitar essas diferenças na sala de aula, mas [...] quando percebo, eu costumo trabalhar com isso (PROF. ${ }^{a}$ AMANDA, 2013 ).

Um menino da sala, não sei se ele é homossexual, mas os colegas dele o julgam como tal. E [...] eu estava dando aula e o pessoal começou a conversar. Aí, pedi para eles fazerem silêncio. E nesse meio tempo o menino falou algo com os outros, pedindo para calarem a boca. Aí, os colegas dele não responderam bem e essa resposta, acredito que foi condicionada ao fato dele ser homossexual, entendeu? Usaram um termo pejorativo. Disseram: 'Que 
Diversidade sexual e homofobia na escola: (des)conhecimento e vivências de docentes

nada, seu viadinho!' E na hora, confesso que não soube o que fazer, como lidar com a situação [...] (PROF. DÊNIS, 2013).

A gente tem em uma turma, um aluno que ele tem aquela voz menos grave e tal, e os alunos consideram que ele tem trejeitos e acaba que os alunos mais danados da turma acabam sempre implicando: 'ah não sei quem é gay, é isso, é aquilo'. Então, percebemos que ele fica meio acuado e cria problema. Sofre, sofre [...] (PROF. DIEGO, 2013).

Ah, sim, sim. Discriminados com violência, são insultados. Com apelidos pejorativos. Um aluno aqui falou pra mim, ainda é uma criança que vinha para escola e alguns colegas do outro lado da rua chamando-o de: 'Viado. Viado! Viado!' Gritando. E já cansei dessa situação. Mas, na nossa sociedade é cultura. Outro foi surrado o ano passado no pátio da escola. Que é uma criança também... Ele é considerado porque ele é meio, tem um jeito diferente. Ele tem uma delicadeza e tal. Então, ou seja, ele é tachado de 'viado', é como muitos colegas se dirigem a ele (PROF. ${ }^{a} J U L I A$, 2013).

É notável a incidência do bullying homofóbico que envolve os preconceitos, as discriminações e as agressões verbais manifestados na escola contra alunos/as não heterossexuais e/ou com identidades de gênero não hegemônicas. Uma das formas de preconceito advém do processo de socialização que dita normas acerca dos papéis e características de cada sujeito. Cabe salientar que existem várias faces de preconceito (nesse caso sexual), que pode ser expresso, de forma mais evidente através da rejeição e discriminação direta (agressões físicas), ou de modo sutil, representado por violências psicológicas que englobam piadas, apelidos pejorativos e variados insultos presentes na linguagem cotidiana e nas representações caricaturais que compõem a homofobia indireta, perpetrada contra a diversidade sexual (BORRILO, 2009; CHOCHÍK, 2006; RIOS, 2009).

Na maioria das escolas, os insultos mais frequentes, que se ouvem nos corredores e/ou na própria sala de aula, são os apelidos pejorativos, tais como "bicha" e "viado". Trata-se de uma forma de intimidar e subestimar os colegas, utilizando um tipo de humilhação que afeta a definição de identidade masculina e desvela o sexismo e a misoginia, ao aproximá-los da identidade feminina. Esses insultos indicam a obrigação de respeitar as normas que enquadram cada sujeito social dentro de uma estreita margem de atuação. Logo, a 
mensagem implícita é: quando alguém rompe as normas recebe uma punição, insultos, isolamentos, vexações e todos os tipos de humilhações que são mais ou menos evidentes e toleradas pelo ambiente social imediato, como a família, escola, o bairro, trabalho, entre outras instâncias sociais (PLATERO, 2008).

A manutenção de estereótipos e ideias preconcebidas acerca das identidades sexuais e de gênero têm reservado a uma parcela significativa de jovens estudantes um lugar social marcado pela experiência de humilhações, constrangimentos, violências físicas ou morais constantes. Embora não se possa determinar, a princípio, a identidade sexual de um indivíduo, as práticas homofóbicas são engendradas por arbitrárias distinções entre o que significa ser heterossexual ou não (ou o que caracteriza o masculino e o feminino). Muitos jovens que começam a sentir desejo por indivíduos do mesmo sexo passam por constrangimentos e acabam acumulando dúvidas e omitindo seus sentimentos, pois, em geral, não encontram na família, nem na escola ou no/a docente uma referência para compartilhar seus questionamentos e angústias acerca da sexualidade. Por isso, o bullying homofóbico tem resultado na evasão escolar de estudantes que expressam identidades sexuais e de gênero distintas do padrão heterossexual, além das tentativas de suicídio de jovens em conflito com sua identidade sexual e de gênero, as quais podem advir dos preconceitos e discriminações sofridos no ambiente escolar (CARRARA; LACERDA, 2011 ; DINIS, 2011 ; LIONÇO; DINIZ, 2009a).

Nesse contexto, destaca-se a necessidade de uma intervenção contínua, sistemática e que os/as educadores/as tomem a frente dessa missão para contribuir com o reconhecimento e a inclusão da diversidade sexual no âmbito escolar, através de ações pedagógicas permanentes e não somente atitudes e/ou intervenções isoladas. Torna-se imprescindível investir em uma revisão do currículo e das relações escolares, privilegiando a igualdade de expressões de gênero e a garantia das vivências plenas das sexualidades. Para tanto, os/ as docentes (e outros membros da escola) deveriam buscar conhecimentos que ensejassem reflexões críticas, visando reconstruir suas representações, a partir da desconstrução das normas, certezas, modelos e dicotomias que marcaram sua formação profissional, e, assim, compreender que a diversidade ao mesmo tempo que tensiona e inquieta também abre espaços para novas possibilidades de vivências e de (re)conhecimento (UUNQUEIRA, 2009a; LOURO, 2000; 2010; RAMIRES, 2011 ; SEFFNER, 2009). 
A desconstrução de condutas homofóbicas constitui um desafio às práticas escolares e aos/as educadores/as. Assim, torna-se fundamental incluir os outros em nossas vidas, seja na escola ou em outras instâncias sociais, não somente pelas semelhanças, mas também pelas diferenças, já que cada indivíduo abriga diversidades, sejam sexuais, socioculturais, étnico-raciais, políticas, entre outras. Dessa maneira, os/as docentes precisariam se preparar para acolher essa diversidade de sujeitos e promover ações pedagógicas que contribuam para o combate a qualquer tipo de preconceito e discriminação, já que a escola deveria ser um ambiente de reflexão e cidadania, onde prevalecem os direitos humanos (CAVALEIRO, 2009). Como foi ressaltado na fala de uma docente "[...] a educação é o encontro das diferenças [...]" (PROF.a AMANDA, 2013).

\section{Considerações finais}

A diversidade sexual, embora permeie a instituição escolar lanalisada), não costuma ser (re)conhecida e nem incluída num contexto democrático, sobretudo porque a insuficiência de conhecimentos dos/as educadores/as (que participaram desta pesquisa), dificulta a promoção de ações pedagógicas contínuas que contribuam para a desconstrução das distintas nuances da homofobia. Assim, ainda que alguns/mas docentes participantes compreendam as graves consequências da homofobia, em geral, permanece no campo cognitivo, mas, não se traduz em ações para combatê-la.

Nesse sentido, esta pesquisa levantou alguns questionamentos: Como (re)conhecer a diversidade sexual e incluíla na escola (de modo democráticol? Como os/as docentes poderiam contribuir com a desconstrução das práticas homofóbicas (diretas e/ou indiretas)? Quais as ações interventivas que poderiam promover o (re)conhecimento da diversidade sexual e o combate à homofobia?

Tais indagações são complexas de responder e, sobretudo, de colocar em prática, entretanto vale ressaltar algumas sugestões que apontam um caminho promissor para o (re)conhecimento da diversidade sexual e desconstrução das práticas homofóbicas sutis e/ou manifestas. Nessa direção, destaca-se a relevância da criação de disciplinas relativas às temáticas sexualidade e gênero em cursos de formação inicial e continuada, projetos de extensão, bem 
como a realização de atividades acadêmicas e pesquisas, voltadas para essa área, aliados à busca de parcerias com escolas e os movimentos LGBT, que seriam meios significativos para possibilitar (in)formações e estimular a discussão desses assuntos no ambiente escolar.

Assim, para que os/as educadores/as, em parceria com os outros membros da escola, possam incentivar além do respeito, o reconhecimento da diversidade (sexual) que ultrapassa o cenário educacional, torna-se fundamental a busca de conhecimentos significativos que permitam problematizar os preconceitos e as discriminações, destacando a importância de compreender as diferenças que compõem as múltiplas vivências e expressões humanas.

\section{Referências}

BARDIN, Laurence. Análise de conteúdo. Lisboa: Edições 70, 2011.

BLAINE, Bruce Evan. Understanding the Psychology of Diversity. Los Angeles: SAGE Publicacions, 2007.

BORRILLO, Daniel. A homofobia. In: LIONÇO, Tatiana; DINIZ, Debora (Org.). Homofobia \& educação: um desafio ao silêncio. Brasília: Letras Livres, 2009.

Homofobia: história e crítica de um preconceito. Belo Horizonte: Autêntica, 2010.

BRASIL. Relatório sobre violência homofóbica no Brasil: o ano de 2011 . Brasília: Secretaria de Direitos Humanos, 2012.

CARRARA, Sérgio; LACERDA, Paula. Viver sob ameaça: preconceito, discriminação e violência homofóbica no Brasil. In: VENTURI, Gustavo; BOKANY, Vilma. Diversidade sexual e homofobia no Brasil. São Paulo: Editora Fundação Perseu Abramo, 2011.

CAVALEIRO, Cristina Maria. Escola e Sexualidades: alguns apontamentos para reflexões. In: FIGUEIRÓ, Mary Neide Damico (Org.). Educação sexual: em busca de mudanças. Londrina: Universidade Estadual de Londrina, 2009.

CHOCHIK, José Leon. Preconceito, indivíduo e cultura. 3. ed. São Paulo: Casa do Psicólogo, 2006.

COSTA, Ronaldo Pamplona da. Os onze sexos: as múltiplas faces da sexualidade humana. São Paulo: Editora Gente, 1994. 
DINIS, Nilson; ASINELLI-LUZ, Araci. Educação sexual na perspectiva histórico-cultural. Educar em Revista, Curitiba, n. 30, p. 77-87, jul./dez. 2007.

DINIS, Nilson Fernandes. Educação, relações de gênero e diversidade sexual. Educação e Sociedade, Campinas, v. 29, n. 103, p. 477-492, maio/ago. 2008.

Homofobia e educação: quando a omissão também é signo de violência. Educar em Revista, Curitiba, n. 39, p. 39-50, jan./abr. 2011.

Educação e diversidade sexual: interfaces Brasil/Canadá. Revista Educação e Cultura Contemporânea, v. 9, n. 18, p. 75-96, 2012.

FIGUEIRÓ, Mary Neide Damico. Diversidade sexual: subsídios para a compreensão e mudança de atitude. In: FIGUEIRÓ, Mary Neide Damico (Org.). Homossexualidade e educação sexual: construindo o respeito à diversidade. Londrina: Universidade Estadual de Londrina, 2007.

FIGUEIRÓ, Mary Neide Damico; KAWATA, Heloísa de Oliveira; NAKAYA, Karen Mayumi. Reeducação sexual: percurso indispensável na formação do/a educador/a. Revista Linhas, Florianópolis, v. 11, n. 1, p. 85-111, jan./jun. 2010.

FLEURY, Alessandra Ramos Demito; TORRES, Ana Raquel Rosas. Homossexualidade e preconceito: o que pensam os futuros gestores de pessoas. Curitiba: Juruá, 2010.

FURLANI, Jimena. Direitos Humanos, Direitos Sexuais e Pedagogia Queer: o que essas abordagens têm a dizer à Educação Sexualẹ In: JUNQUEIRA, Rogério Diniz (Org.). Diversidade sexual na educação: problematizações sobre a homofobia nas escolas. Brasília: Ministério da Educação, Secretaria de Educação Continuada, Alfabetização e Diversidade, UNESCO, 2009.

HENRIQUES, Ricardo; BRANDT, Maria Elisa Almeida; JUNQUEIRA, Rogério Diniz; CHAMUSCA, Adelaide (Org.). Gênero e diversidade sexual na escola: reconhecer diferenças e superar preconceitos. Brasília, Cadernos Secad, 2007.

HEREK, Gregory Michael. The psychology of sexual prejudice. Current directions in psychological science, United States, v. 9, n. 1, p. 19-22, February, 2000.

JUNQUEIRA, Rogério Diniz. Educação e Homofobia: o reconhecimento da diversidade sexual para além do multiculturalismo liberal. In: JUNQUEIRA, Rogério Diniz (Org.). Diversidade sexual na educação: problematizações sobre a homofobia nas escolas. Brasília: Ministério da Educação, Secretaria de Educação Continuada, Alfabetização e Diversidade, UNESCO, 2009. 
Políticas de educação para a diversidade sexual: escola como lugar de direitos. In: LIONÇO, Tatiana; DINIZ, Debora (Org.). Homofobia \& educação: um desafio ao silêncio. Brasilia: Letras Livres/EdUnB, 2009a.

KAMEL, Luciana; PIMENTA, Cristina. Diversidade sexual nas escolas: o que os profissionais de educação precisam saber. Rio de Janeiro: ABIA, 2008.

LIMA, Marcus Eugênio Oliveira; VALA, Jorge. As novas formas de expressão do preconceito e do racismo. Estudos de Psicologia, Natal, v. 9, n. 3, p. $401-41$ 1, set./dez. 2004.

LIONÇO, Tatiana; DINIZ, Débora. Qual a diversidade sexual dos livros didáticos Brasileiros? In: LIONÇO, Tatiana; DINIZ, Débora (Org.). Homofobia \& educação: um desafio ao silêncio. Brasília: Letras Livres/EdUnB, 2009.

Homofobia, silêncio e naturalização: por uma narrativa da diversidade sexual. In: LIONÇO, Tatiana; DINIZ, Débora (Org.). Homofobia \& educação: um desafio ao silêncio. Brasilia: Letras Livres/EdUnB, 2009a.

LOURO, Guacira Lopes. Gênero, sexualidade e educação: Uma perspectiva pós-estruturalista. 2. ed. Petrópolis: Vozes, 1997.

Pedagogias da sexualidade. In: LOURO, Guacira Lopes (Org.). O corpo educado: pedagogias da sexualidade. 2. ed. Belo Horizonte: Autêntica, 2000.

Heteronormatividade e Homofobia. In: JUNQUEIRA, Rogério Diniz (Org.). Diversidade sexual na educação: problematizações sobre a homofobia nas escolas. Brasília: Ministério da Educação, Secretaria de Educação Continuada, Alfabetização e Diversidade, UNESCO, 2009.

Sexualidades minoritárias e educação: novas políticas? In: POCAHY, Fernando (Org.). Políticas de enfrentamento ao heterossexismo: corpo e prazer. Porto Alegre: Nuances, 2010.

MADUREIRA, Ana Flávia do Amaral. Gênero, sexualidade e diversidade sexual na escola: a construção de uma cultura democrática (Tese de doutorado). Brasília: Universidade de Brasília, 2007.

MEYER, Dagmar Elisabeth Estermann. Gênero e educação: teoria e política. In: LOURO, Guacira Lopes; FELIPE, Jane; GOELLNER, Silvana Vilodre (Org.). Corpo, gênero e sexualidade: um debate contemporâneo na educação. 9. ed. Petrópolis: Vozes, 2013.

NOGUEIRA, Conceição; SAAVEDRA, Luísa. Estereótipos de gênero: conhecer para os transformar. In: Caderno SACAUSEF III - A dimensão de género nos produtos educativos 
multimédia. Lisboa: Ministério da Educação - Direção Geral de Inovação e Desenvolvimento Curricular, 2007.

PEREIRA, Graziella Raupp. Decursos educativos e conhecimentos para uma educação sexual emancipatória intencional. Revista Linhas, Florianópolis, v. 11, n. 01, p. 53-67, jan./jun. 2010.

PLATERO, Raquel. La homofobia como elemento clave del acoso escolar homofóbico. Algunas voces desde Rivas Vaciamadrid. Información Psicológica, Valencia, n. 94, p.71-83, sep./ dic. 2008 .

PROF. AFONSO. Entrevista. Simão Dias (Sergipe), 14 nov. 2013.

PROF.' AMANDA. Entrevista. Simão Dias (Sergipe), 14 nov. 2013.

PROF. ${ }^{a}$ ARIELLA. Entrevista. Simão Dias (Sergipe), 25 nov. 2013.

PROF. DENIS. Entrevista. Simão Dias (Sergipe), 25 nov. 2013.

PROF. DIEGO. Entrevista. Simão Dias (Sergipe), 25 nov. 2013.

PROF. ELIAS. Entrevista. Simão Dias (Sergipe), 6 dez. 2013.

136 PROF. ${ }^{a}$ JULIA. Entrevista. Simão Dias (Sergipe), 14 nov. 2013.

PROF. RAFAEL. Entrevista. Simão Dias (Sergipe), 14 nov. 2013.

PROF. RAUL. Entrevista. Simão Dias (Sergipe), 25 nov. 2013.

PROF. ${ }^{a}$ VANUZA. Entrevista. Simão Dias (Sergipe), 6 nov. 2013.

RAMIRES, Luiz. Homofobia na escola: o olhar de um educador. In: VENTURI, Gustavo; BOKANY, Vilma (Org.). Diversidade sexual e homofobia no Brasil. São Paulo: Editora Fundação Perseu Abramo, 2011.

RIOS, Roger Raupp. Homofobia na perspectiva dos direitos humanos e no contexto dos estudos sobre preconceito e discriminação In: JUNQUEIRA, Rogério Diniz (Org.). Diversidade sexual na educação: problematizações sobre a homofobia nas escolas. Brasília: Ministério da Educação, Secretaria de Educação Continuada, Alfabetização e Diversidade, UNESCO, 2009.

SEFFNER, Fernando. Equívocos e armadilhas na articulação entre diversidade sexual e políticas de inclusão escolar. In: JUNQUEIRA, Rogério Diniz (Org.). Diversidade sexual na educação: problematizações sobre a homofobia nas escolas. Brasília: Ministério da 
Educação, Secretaria de Educação Continuada, Alfabetização e Diversidade, UNESCO, 2009.

SILVA JÚNIOR, Jonas Alves. Rompendo a mordaça: representações sociais de professores e professoras do ensino médio sobre homossexualidade. 2010. 300f. Tese (Doutorado em Educação) - Programa de Pós-Graduação em Educação, Universidade de São Paulo, São Paulo, 2010.

TOSSO, Melani Penna. Formación del profesorado en la atención a la diversidad afectivo-sexual. 2012.671f. Tesis (Doctoral en Educación) - Faculdad de Educación, Universidad Complutense de Madrid, Madrid, 2012.

WELZER-LANG, Daniel. A construção do masculino: dominação das mulheres e homofobia.

Revista Estudos Feministas, Florianópolis, v. 9, n. 2, p. 460-482, jul./dez. 2001.

$$
\begin{array}{r}
\text { Doutoranda Elaine de Jesus Souza } \\
\text { Universidade Federal do Rio Grande do Sul | Porto Alegre } \\
\text { Faculdade de Educação } \\
\text { Programa de Pós-Graduação em Educação }
\end{array}
$$
Grupo de Pesquisa Gênero, Sexualidade e Estudos Culturais | CNPq Bolsista CNPq Email | elaine.js.sd@hotmail.com Prof. Dr. Joilson Pereira da Silva Universidade Federal de Sergipe | São Cristóvão Departamento de Letras Estrangeiras Núcleo de Pós-Graduação em Psicologia Social Grupo de Pesquisa Gênero, Sexualidade e Estudos Culturais | CNPq Email | joilsonp@hotmail.com Profa. Dra. Claudiene Santos 
Artigo

Diversidade sexual e homofobia na escola: (des)conhecimento e vivências de docentes

Universidade Federal de Sergipe | São Cristóvão

Departamento de Biologia

Núcleo de Pós-Graduação em Psicologia Social

Líder do Grupo de Pesquisa Gênero, Sexualidade e Estudos Culturais |CNPq

Email | claudienesan@gmail.com

Recebido 25 out. 2014

Aceito 2 maio 2016 